Pesq. Vet. Bras. 31(3):224-230, março 2011

\title{
Linfadenite caseosa em ovinos deslanados abatidos em um frigorífico da Paraíba ${ }^{1}$
}

\author{
Maria de Fátima Souza², Amanda Q. de Carvalho ${ }^{3}$, Felício Garino $\mathrm{Jr}^{3}$ \\ e Franklin Riet-Correa ${ }^{3 *}$
}

\begin{abstract}
Souza M.F., Carvalho A.Q., Garino Jr F. \& Riet-Correa F. 2011. [Caseous lymphadenitis in slaughtered hair sheep in northeastern Brazil.] Linfadenite caseosa em ovinos deslanados abatidos em um frigorífico da Paraíba. Pesquisa Veterinária Brasileira 31(3):224-230. Hospital Veterinário, CSTR, Universidade Federal de Campina Grande, Patos, PB 58700-000, Brazil. E-mail: franklin.riet@pq.cnpq.br

The objective of this paper is to report the prevalence and distribution of lesions of caseous lymphadenitis $(\mathrm{CL})$ in hair sheep slaughtered in an abattoir in the state of Paraíba, northeastern Brazil. From 1,466 sheep slaughtered, $236(15.9 \%)$ had gross lesions similar to that of CL. The prevalence was higher in females, $17.9 \%$ (135/754), than in males, $13.8 \%$ $(101 / 732)$. Ninety seven (36.3\%) out of 268 lesions were localized in the prescapular lymph node, $22.4 \%$ (60/268) in the parotideal, and $20.9 \%$ (56/268) in the prefemoral. Only $70(26.1 \%)$ out of 268 lesions suggestive of CL were detected during ante mortem examination. Caseous lymphadenitis-like lesions were observed in all flocks examined from different municipalities in the states of Paraíba, Pernambuco and Bahia. Cultures and histologic examination were performed in samples from 51 lesions. Corynebacterium pseudotuberculosis was isolated in $74.5 \%$ (43/51) samples, Staphylococcus aureus in 7.8\% (4/51) samples, Escherichia coli in $2 \%(1 / 51)$, and in $5.9 \%(3 / 51)$ samples cultures were negative. Histologic findings in 11 lymph nodes showed all characteristic lesions of caseous lymphadenitis: central area of necrosis formed by concentric lamellae, with large bacterial colonies and mineralization, surrounded by an inflammatory exudate with epithelioid macrophages and few neutrophils; lymphocytes and plasma cells were observed in the next layer, and fibrous tissue was surrounding the whole lesion. Lesions in the other 32 lymph nodes showed most, but not all lesions characteristic of the disease. Giant cells were observed in 21 lymph nodes. Histologic lesions in lymph nodes from which $S$. aureus was isolated were similar as those of CL. These findings suggest that $C L$ lesions are characteristic, but not pathognogmonic, because they can be confused with lesions caused by other pyogenic bacteria or tuberculosis; therefore bacteriologic examination is necessary for the diagnosis of the disease.
\end{abstract}

INDEX TERMS: Caseous lymphadenitis, sheep, Corynebacterium pseudotuberculosis, ante mortem examination, post mortem examination.

RESUMO.- Este trabalho teve como objetivo determinar a prevalência e distribuição de lesões da linfadenite caseosa em ovinos deslanados abatidos no município de Mulun-

\footnotetext{
${ }^{1}$ Recebido em 6 de julho de 2010.

Aceito para publicação em 6 de outubro 2010.

${ }^{2}$ Curso de Especialização em Defesa Sanitária, Higiene e Inspeção de Produtos de Origem Animal (Equalis Nordeste), Rua Aderaldo da Silveira Souza 121, Apto 102 B, Condomínio Novo Horizonte III, Jardim São Paulo, João Pessoa, PB 58053-120, Brasil.

${ }^{3}$ Hospital Veterinário, Centro de Saúde e Tecnologia Rural (CSTR), Universidade Federal de Campina Grande (UFCG), Patos, PB 58700000. *Autor para correspondência: franklin.riet@pq.cnpq.br
}

gu, Paraíba. Dos 1466 ovinos abatidos, 236 (15,9\%) apresentaram lesões macroscópicas semelhantes à linfadenite caseosa. A prevalência foi maior em fêmeas, $17.9 \%$ (135/754) que em machos, 13,8\% (101/732). As principais lesões estavam localizadas nos linfonodos pré-escapulares em $36,3 \%$ (97/268) dos ovinos, nos parotídeos em $22,4 \%$ $(60 / 268)$ e no pré-crural em 20,9\% (56/268). Somente 70 $(26,1 \%)$ de um total de 268 lesões foram detectadas no exame ante mortem. Foram encontradas lesões em todos os lotes provenientes de diversos municípios da Paraíba, Pernambuco e Bahia. Das 51 amostras em que foi feito o cultivo bacteriológico, em 74,5\% (43/51) foi isolado Cory- 
nebacterium pseudotuberculosis. Em 7,8\% (4/51) foi isolado Staphylococcus aureus, em 2\% (1/51) Escherichia coli e 5,9\% (3/51) amostras foram negativas. No exame histológico, em 11 linfonodos havia lesões da linfadenite caseosa caracterizadas por área de necrose central formada por lamelas concêntricas, com presença de grandes colônias bacterianas e focos de mineralização, rodeada por uma faixa de infiltrado inflamatório com macrófagos epitelióides e poucos neutrófilos. Na camada adjacente observaram-se linfócitos e plasmócitos e toda a lesão era delimitada por tecido conjuntivo fibroso. Nas outras 32 amostras foram observadas a maioria, mas não todas as lesões características da doença. Em 21 amostras foram encontradas células gigantes. As lesões histológicas dos linfonodos que foi isolado $S$. aureus foram semelhantes as da linfadenite caseosa. Conclui-se que as lesões histológicas de linfadenite caseosa são características, mas não patognomônicas, pois podem ser confundidas com lesões causadas por outros organismos piógenos e com tuberculose; portanto o isolamento bacteriológico é imprescindível para o diagnóstico definitivo da linfadenite caseosa.

TERMOS DE INDEXAÇÃO: Linfadenite caseosa, ovinos, Corynebacterium pseudotuberculosis, exame ante mortem, exame post mortem, lesões subclínicas.

\section{INTRODUÇÃO}

A ovinocultura de corte é uma atividade importante para o desenvolvimento sócio-econômico do semiárido brasileiro. Um dos fatores limitantes desta atividade é o alto índice de doenças contagiosas, dentre elas a linfadenite caseosa. Esta é definida como uma enfermidade crônica contagiosa que acomete ovinos e caprinos, caracterizada por lesões purulentas e caseosas nos linfonodos, e, ocasionalmente, pulmões, baço, rins, fígado e sistema nervoso central (Smith \& Sherman 1994, Alves et al. 2007, Radostits et al. 2007, Riet-Correa 2007).

A forma clínica se caracterizada por abscessos localizados nos linfonodos superficiais ou na pele. Outra forma clínica denominada "síndrome da ovelha magra" caracteriza-se por emagrecimento progressivo e ocorre mais em ovinos que em caprinos (Alves et al. 2007, Riet-Correa 2007).

A linfadenite caseosa é responsável por grandes perdas econômicas na indústria ovina e caprina, devido a sua alta incidência que causa condenação das carcaças, desvalorização da pele devido a cicatrizes deixadas pelos abscessos, diminuição da produção de carne ou leite, gastos com tratamentos e ocasionalmente morte dos animais acometidos (Smith \& Sherman 1994, Alves et al. 2007, Radostits et al. 2007, Riet-Correa 2007).

O agente etiológico da linfadenite caseosa é Corynebacterium pseudotuberculosis, bactéria Gram-positiva, não esporulada, aeróbica e parasita intracelular facultativa de macrófagos. Produz uma exotoxina, a fosfolipase D, que atua como esfingomielinase, que é dermonecrótica, hemolítica, causa supuração e tem ação nas células endoteliais, causando aumento da permeabilidade dos vasos sanguíneos e linfáticos facilitando desta maneira a invasão bacteriana. É um parasito intracelular facultativo e possui um lipídio de superfície, leucotóxico, que protege a bactéria da fagocitose (Alves et al. 2007, Fontaine \& Baird 2008).

A doença é endêmica no Brasil, e tem uma prevalência clínica variável de $5 \%$ a $50 \%$, sendo mais comum em caprinos e ovinos deslanados (Silva \& Silva 1982, Unanian et al. 1985, Langenegger et al. 1991, Riet-Correa et al. 2003, Veschi 2005, Alves et al. 2007, Andrade 2007). A principal fonte de infecção é o conteúdo dos abscessos que quando supuram, contaminam o meio ambiente. A transmissão ocorre por contato direto com as secreções dos abscessos ou mediada por agulhas, aparelhos de tosquia, instalações, fômites e banhos de imersão contaminados com o agente (Alves et al. 2007, Radostits et al. 2007, Riet-Correa 2007).

Os sinais clínicos encontrados são aumento de tamanho de um ou mais linfonodos superficiais que possam romper-se com facilidade. A maioria das lesões (70-90\%) ocorre nos linfonodos pré-escapulares, retrofarígeos, parotídeos, sub-mandibulares e pré-crurais possivelmente por estas áreas serem as mais frequentemente afetadas por escoriações e outras lesões traumáticas que facilitam a penetração do organismo (Smith \& Sherman 1994, Alves et al. 2007, Radostits et al.2007).

Nos abscessos geralmente encontra-se conteúdo com coloração que varia do branco ao amarelado e ou esverdeado, inodoro e com consistência inicial pastosa que finalmente se torna dura e seca com uma aparência laminada (semelhante a uma cebola cortada transversalmente) mais característica nos ovinos (Smith \& Sherman 1994, Radostits et al. 2007, Riet-Correa 2007, Fontaine \& Baird 2008). O diagnóstico se baseia no exame clínico, momento em que se observa a presença de um abscesso de consistência firme a ligeiramente flutuante na região anatômica de um linfonodo superficial (Smith \& Sherman 1994). O diagnóstico definitivo só é realizado mediante exames bacteriológicos e histológicos. A lesão histológica da linfadenite caseosa é caracterizada principalmente, pela presença de lamelas concêntricas na área de necrose que se formam por que durante o crescimento do abscesso há progressiva necrose e re-formação da cápsula fibrosa (Fontaine \& Baird 2008).

O tratamento baseia-se no corte e abertura do abscesso maduro, seguido de limpeza do local com iodo a $10 \%$. Os animais doentes devem ser isolados e só devem voltar ao rebanho após a cicatrização total do abscesso. Existem vacinas no mercado que conferem proteção variável (Radostits et al. 2007, Riet-Correa 2007).

Este trabalho foi realizado com os objetivos de determinar a prevalência e distribuição de lesões da linfadenite caseosa em ovinos abatidos em um frigorífico com Serviço de Inspeção Federal no agreste da Paraíba, assim como estudar as lesões histológicas e identificar o agente causal em lesões macroscopicamente semelhantes à linfadenite caseosa encontradas durante o abate.

\section{MATERIAL E MÉTODOS}

Esta pesquisa foi realizada no Frigorífico Caprino, especializado em abate e beneficiamento de carnes e miúdos de caprinos e 
ovinos com o Serviço de Inspeção Federal (SIF), localizado na Zona Rural de Mulungu Paraíba, no período de 3.6.2009 a 4.11.2009.

Todos os animais dos lotes destinados ao abate foram observados e examinados por palpação dos linfonodos superficiais (pré-escapulares, parotídeos, submandibulares, précrurais, retromamários) para identificar os linfonodos com lesões sugestivas de linfadenite caseosa, em seguida foi verificado a idade, através da cronologia dentária, e o sexo. No decorrer do exame post mortem, realizado pelo SIF, foram realizados cortes nos linfonodos de acordo com a linha de inspeção para identificar lesões semelhantes à linfadenite caseosa. Foram consideradas lesões clínicas as encontradas durante o exame ante mortem e como subclínicas as que somente foram detectadas no exame post mortem.

Para o exame bacteriológico foram coletadas 51 amostras, durante seis visitas periódicas ao frigorífico, sendo que em cada visita eram coletadas todas as lesões suspeitas macroscopicamente de serem linfadenite caseosa. No total foram coletadas amostras de 10 dos 35 lotes abatidos durante o experimento. Para o exame microbiológico, as amostras foram coletadas após

\section{Quadro 1. Distribuição das lesões macroscópicas de linfadenite caseosa diagnosticadas nos exames ante mortem e post mortem em ovinos abatidos no período de 3.6.2009 a 3.11.2009 em um Frigorífico na Paraíba}

\begin{tabular}{lcc}
\hline \multicolumn{1}{c}{$\begin{array}{c}\text { Órgão } \\
\text { acometido }\end{array}$} & $\begin{array}{c}\text { Ante mortem } \\
\text { Número }(\%)\end{array}$ & $\begin{array}{c}\text { Post mortem } \\
\text { Número }(\%)\end{array}$ \\
\hline Linfonodo pré-crural & $26(37,1)$ & $56(20,9 \%)$ \\
Linfonodo parotídeo & $15(21,4)$ & $60(22,4 \%)$ \\
Linfonodo pré-escapular & $26(37,1)$ & $97(36,3 \%)$ \\
Linfonodo retrofaríngeo & 0 & $9(3,3 \%)$ \\
Linfonodos mediastínicos & 0 & $30(11,2 \%)$ \\
e brónquicos & $2(2,9)$ & $1(0,4 \%)$ \\
Linfonodo retromamário & 0 & $1(0,4 \%)$ \\
Linfonodo ilíaco & 0 & $3(1,1 \%)$ \\
Linfonodo poplíteo & $1(1,4)$ & $2(0,7 \%)$ \\
Linfonodo submandibular & 0 & $1(0,4 \%)$ \\
Linfonodo mesentérico & 0 & $6(2,2 \%)$ \\
Fígado & 0 & $2(0,7 \%)$ \\
Pulmão & $70(100 \%)$ & $268(100 \%)$ \\
Total de lesões &
\end{tabular}

a Inclui todas as lesões encontradas, as que foram encontradas no exame ante-mortem e as que somente foram encontradas no exame post-mortem. a inspeção post mortem, através de suabes estéreis. Os suabes foram transferidos para tubos de ensaios contendo meio Stuart (Himedia ${ }^{\circledR}$, Bhaveshwar, Mumbai, India) e acondicionados em caixas isotérmicas e encaminhadas ao laboratório de microbiologia do Hospital Veterinário da UFCG sob refrigeração. No laboratório, as amostras foram semeadas em meio Agar Sangue Ovino 5\% (Himedia ${ }^{\circledR}$, Bhaveshwar, Mumbai, India) e Brain Heart Infusion broth (BHI-Himedia ${ }^{\circledR}$, Bhaveshwar, Mumbai, India), incubadas a $37^{\circ} \mathrm{C}$ em aerobiose, sendo realizadas leituras com 24 a 72 horas de incubação. Nos microrganismos isolados foram realizados exames bacterioscópicos pelo método de Gram e submetidos às provas de identificação. As provas utilizadas foram: produção de catalase, uréase e indol; coagulação de plasma de coelho; motilidade em ágar semi-sólido; hidrólise da esculina; acidificação de carboidratos; oxidação-fermentação em meio de Hugh e Leifson; redução de nitrato; cultivo em TSI e ágar citrato de Simmons; e testes de Camp, VM/VP e oxidase. Os agentes etiológicos foram identificados baseandose no Manual of Clinical Microbiology (Murray et al. 1999).

Para o estudo histológico, fragmentos dos mesmos linfonodos coletados para o estudo bacteriológico foram fixados em formalina a $10 \%$, emblocados em parafina e cortados com $5 \mu \mathrm{m}$ de espessura. Posteriormente, foram corados por Hematoxilina - Eosina (HE), Gram, Von Kossa, Àcido Periódico de Schiff (PAS) e Ziehl-Neelsen.

\section{RESULTADOS}

Todos os ovinos abatidos eram deslanados, principalmente da raça Santa Inês e suas cruzas. Nesta pesquisa, 4,7\% (70/1486) dos animais apresentaram lesões semelhantes à linfadenite caseosa no exame ante mortem, enquanto que no exame post mortem 15,9\% (236/1486) dos animais apresentaram lesões macroscópicas semelhantes à linfadenite caseosa.

A localização das lesões observadas no exame ante e post mortem apresentam-se no Quadro 1. A localização das lesões segundo a idade e o sexo apresenta-se no Quadro 2. A prevalência em machos foi de 13,8\% (101/ 732) e em fêmeas de 17,9\% (135/754). A prevalência de linfadenite caseosa por município de origem encontra-se no Quadro 3. Neste trabalho, alem de dois ovinos com linfadenite caseosa retirados dos lotes de abate para tratamento, deixaram de ser comercializadas $39(2,6 \%)$ con-

Quadro 2. Distribuição das lesões de linfadenite caseosa em ovinos abatidos segundo idade e sexo

\begin{tabular}{|c|c|c|c|c|c|c|c|c|c|c|c|c|c|}
\hline \multirow{2}{*}{$\begin{array}{c}\text { Idade/ } \\
\text { sexo }\end{array}$} & \multicolumn{8}{|c|}{ Linfonodos superficiais } & \multicolumn{2}{|c|}{ Linfonodos internos } & \multicolumn{2}{|c|}{ Òrgãos } & \multirow{2}{*}{$\begin{array}{l}\text { Total } \\
\mathrm{N}(\%)\end{array}$} \\
\hline & $\begin{array}{c}\text { Pré-crural } \\
\mathrm{N}(\%)\end{array}$ & $\begin{array}{c}\text { Parotídeo } \\
\mathrm{N}(\%)\end{array}$ & $\begin{array}{c}\text { Pré- } \\
\text { escapular } \\
\mathrm{N}(\%)\end{array}$ & $\begin{array}{c}\text { Retrofa- } \\
\text { ríngeo } \\
\mathrm{N}(\%)\end{array}$ & Poplíteo & $\begin{array}{l}\text { Submandi- } \\
\text { bular }\end{array}$ & $\begin{array}{l}\text { Retroma- } \\
\text { mário }\end{array}$ & llíaco & $\begin{array}{l}\text { Mediastí- } \\
\text { nicoN(\%) }\end{array}$ & $\begin{array}{c}\text { Mesen- } \\
\text { téricos } \\
\mathrm{N}(\%)\end{array}$ & $\begin{array}{c}\text { Figado } \\
\mathrm{N}(\%)\end{array}$ & $\begin{array}{c}\text { Pulmão } \\
\mathrm{N}(\%)\end{array}$ & \\
\hline $\mathrm{DL} / \mathrm{F}$ & $9(17,6)$ & $9(17,6)$ & $27(52,9)$ & $3(5,9)$ & 0 & 0 & 0 & 0 & $2(3,9)$ & 0 & $1(2)$ & 0 & $51(100)$ \\
\hline $2 \mathrm{D} / \mathrm{M}$ & $7(22,6)$ & $7(22,6)$ & $8(25,8)$ & $0(0)$ & $1(3,2)$ & 0 & 0 & 0 & $6(19,3)$ & 0 & $2(06,4)$ & 0 & $31(100)$ \\
\hline $2 \mathrm{D} / \mathrm{F}$ & $5(21,7)$ & $5(21,7)$ & $10(43,4)$ & $0(0)$ & $1(4,3)$ & 0 & 0 & 0 & $1(4,3)$ & 0 & $1(4,3)$ & 0 & $23(100)$ \\
\hline $6 \mathrm{D} / \mathrm{M}$ & $2(25)$ & $4(50)$ & 0 & $1(12,5)$ & 0 & 0 & 0 & 0 & 0 & 0 & 0 & $1(12,5)$ & $8(100)$ \\
\hline $6 \mathrm{D} / \mathrm{F}$ & $6(27,3)$ & $3(13,6)$ & $7(31,8)$ & $2(9,1)$ & 0 & 0 & 0 & 0 & $4(18,1)$ & 0 & 0 & 0 & $22(100)$ \\
\hline $\mathrm{BC} / \mathrm{F}$ & $5(23,8)$ & $2(9,5)$ & $4(19)$ & $1(4,8)$ & 0 & 0 & $1(4,8)$ & $1(4,8)$ & $6(28,6)$ & 0 & $1(4,8)$ & 0 & 21(100) \\
\hline Total & $56(20,9)$ & $60(22,4)$ & $97(36,2)$ & $9(3,4)$ & $3(1,1)$ & $2(0,7))$ & $1(0,4)$ & $1(0,4)$ & $30(11,2)$ & $1(0,4)$ & $6(2,2)$ & $2(0,7)$ & $268(100)$ \\
\hline
\end{tabular}

a $\mathrm{DL}=$ dente de leite; $2 \mathrm{D}=1^{\mathrm{a}}$ muda; $4 \mathrm{D}=2^{\mathrm{a}}$ muda; $6 \mathrm{D}=3^{\mathrm{a}}$ muda; $\mathrm{BC}=$ boca cheia; $\mathrm{M}=$ macho. $\mathrm{F}=$ fêmea. 


\section{Quadro 3. Prevalência de ovinos com lesões post mortem semelhantes à linfadenite caseosa de diferentes procedências}

\begin{tabular}{ccccccc}
\hline $\begin{array}{c}\text { Procedência } \\
\text { (Município) }\end{array}$ & $\begin{array}{c}\text { Ovinos } \\
\text { abatidos, } \\
\text { por sexo }\end{array}$ & $\begin{array}{c}\text { Total } \\
\text { ovinos } \\
\text { abatidos }\end{array}$ & $\begin{array}{c}\text { Posi- } \\
\text { tivos } \\
\mathrm{n}(\%)\end{array}$ & $\begin{array}{c}\text { Posi- } \\
\text { tivos } \\
\mathrm{n}(\%)\end{array}$ & $\begin{array}{c}\text { Total } \\
\text { posi- } \\
\text { tivos } \\
\text { Machos }\end{array}$ & $\begin{array}{c}\text { Fêmeas } \\
\mathrm{n}(\%)\end{array}$ \\
\hline Jussara-BA & 153 & 145 & 298 & $21(7)$ & $26(8,8)$ & $47(15,8)$ \\
Mulungu-PB & 22 & 131 & 153 & $7(4,6)$ & $36(23,5)$ & $43(28,1)$ \\
S.Bomfim-BA & 287 & 233 & 520 & $41(7,9)$ & $37(7,1)$ & $78((15)$ \\
Remanso-BA & 160 & 97 & 257 & $15(5,8)$ & $8(3,1)$ & $23(8,9)$ \\
São João Cariri-PB & 59 & 38 & 97 & $15(15,5)$ & $9(9,2)$ & $24(24,7)$ \\
Ingá-PB & 25 & 5 & 30 & $0(0)$ & $1(3,3)$ & $1(3,3)$ \\
Areia-PB & 11 & 50 & 61 & $0(0)$ & $8(13,1)$ & $8(13,1)$ \\
Floresta-PE & 15 & 55 & 70 & $1(1,4)$ & $10(14,3)$ & $11(15,7)$ \\
Total & 732 & 754 & 1486 & 101 & 135 & 236
\end{tabular}

juntos de vísceras vermelhas e $3(0,2 \%)$ carcaças, devido a lesões causadas pela doença.

No exame microbiológico Corynebacterium pseudotuberculosis cresceu em meio ágar sangue, formando pequenas colônias de coloração branco-acinzentada, opacas e friáveis, após 24-48 horas de cultivo. Apresentou-se como um bacilo Gram positivo curto e irregular, medindo 0,5$0,6 \mu \mathrm{m}$ por $1-3 \mu \mathrm{m}$, com aspecto cocóide, mostrando-se iso- lado ou formando grupamentos irregulares ou em paliçada. Dos 51 linfonodos com lesões nos quais foi feito cultivo, $47(86,3 \%)$ apresentaram isolamento bacteriológico, sendo $43(74,5 \%)$ positivos para C. pseudotuberculosis, 3 $(7,8 \%)$ para Staphylococcus aureus, $1(2 \%)$ para Escherichia coli e $3(5,9 \%)$ foram bacteriologicamente negativos.

As lesões macroscópicas foram caracterizadas por abscessos com conteúdo amarelo-esverdeado ou branco-amarelado de consistência variando de purulenta a caseosa. Histologicamente, das 43 amostras nas que foi isolado $C$. pseudotuberculosis, $11(21,6 \%)$ apresentaram lesões histológicas consideradas como características da doença, com uma área de necrose central composta de restos celulares e formada por lamelas concêntricas (Fig.1A,B) e presença de grandes colônias bacterianas (Fig.1C,D). Esta área estava circundada por uma faixa de infiltrado inflamatório, constituído predominantemente por macrófagos epitelióides e poucos neutrófilos sendo a maioria destes degenerados. $\mathrm{Na}$ camada adjacente observaram-se linfócitos e plasmócitos, sendo a lesão delimitada por tecido conjuntivo fibroso que varia de moderado a abundante (Fig.2). Essas 11 amostras apresentaram também focos de mineralização na área de necrose. Em quatro linfonodos não foi possível visualizar a presença de grandes colônias, mineralização e/ou as ca-
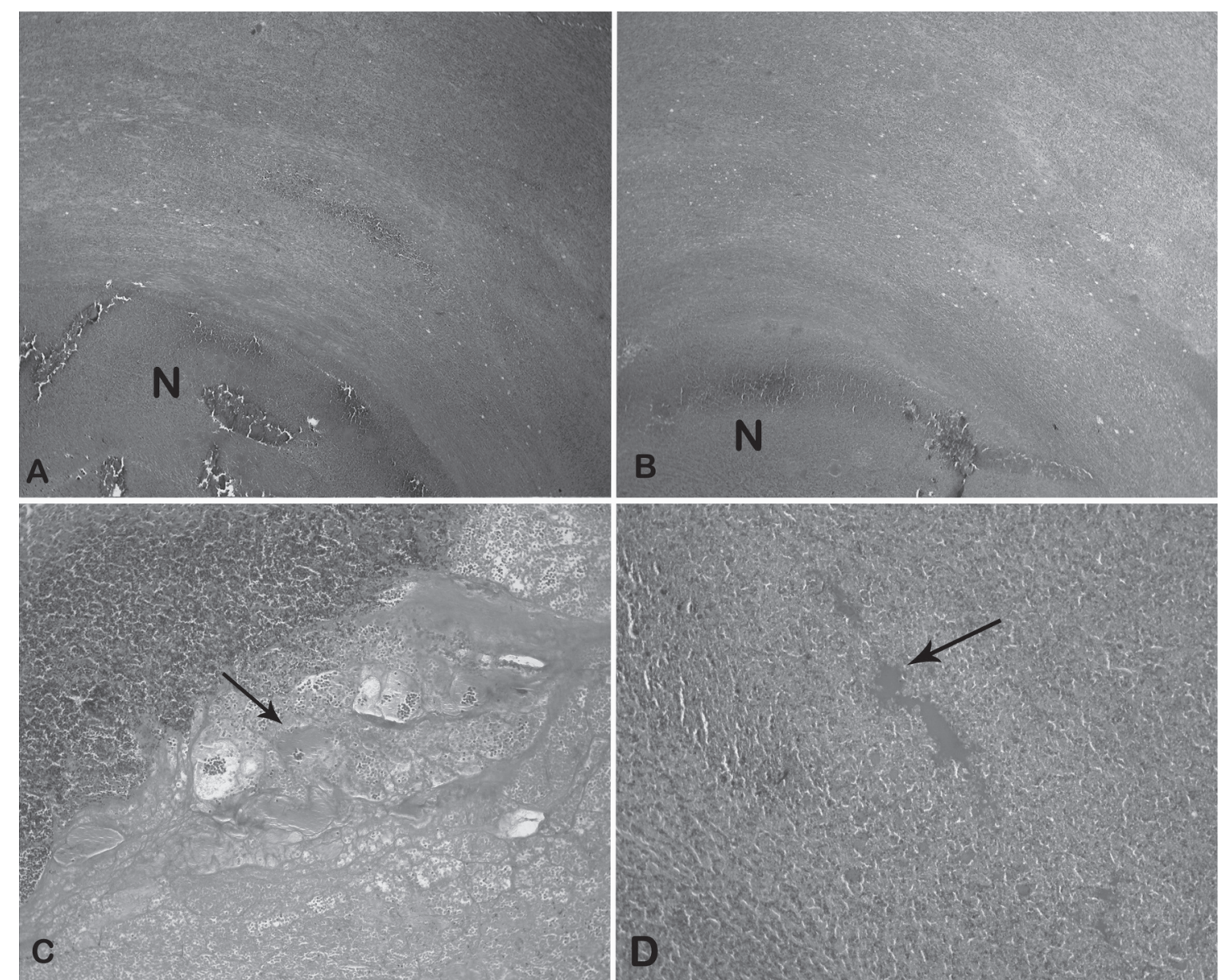

Fig.1. Linfonodos de ovinos com linfadenite caseosa. (A,B) Lamelas concêntricas na área de necrose (N). (C,D) Grandes colônias bacterianas de Corynebacterium pseudotuberculosis (setas). HE, obj.10x. 


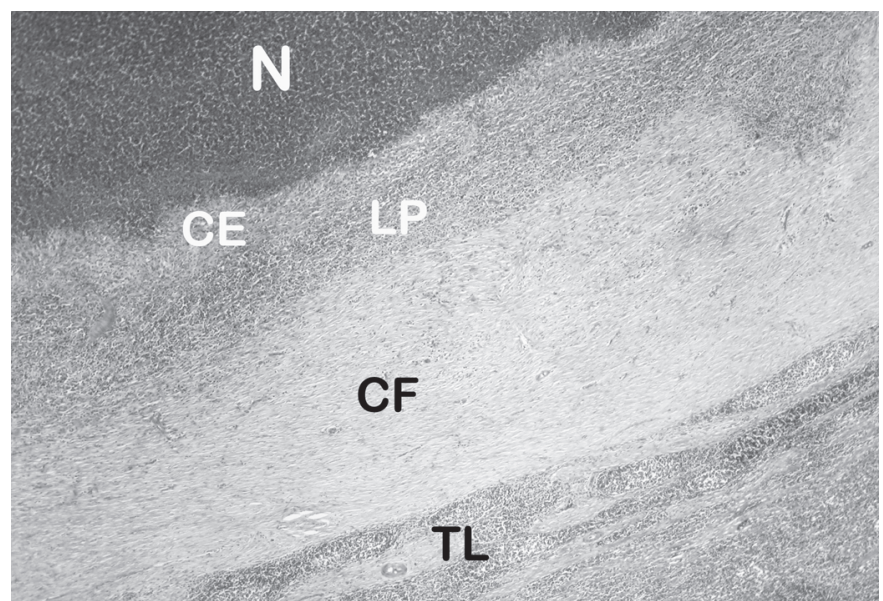

Fig.2. Linfonodo de ovino com lesões de linfadenite caseosa mostrando a organização tecidual característica. No centro observa-se uma área de necrose $(\mathrm{N})$ circundada por uma faixa de infiltrado inflamatório, constituído predominantemente por macrófagos epitelióides (CE). Na camada adjacente observam-se linfócitos e plasmócitos (LP) e a lesão é delimitada por tecido conjuntivo fibroso (CF). $T L=$ Tecido linfático. HE, obj.10x.

madas lamelares, pois no momento da preparação histológica a área de necrose se desprendeu do fragmento ou a mesma não foi incluída na amostra. Em relação à freqüência de lesões consideradas características de linfadenite caseosa, das 39 amostras nas que se isolou C. pseudotuberculosis no exame bacteriológico e foi possível observar a área de necrose, 97,4\% (38/39) apresentaram mineralização e 59\% (23/39) apresentaram grandes colônias. Em 21 $(53,8 \%)$ amostras foram observadas células gigantes em número de um a cinco em todo o corte histológico, sendo que em 10 foram encontradas 1 ou 2 células gigantes em todo o corte, em 5 encontraram-se de 3 a 5 células gigantes, e em 6 mais de 5 . Em 25 (64,11\%) casos foram observadas lamelas concêntricas na área de necrose e 34 (87,2\%) apresentavam a organização tecidual característica da linfadenite caseosa. As lesões nas que não se observava a organização tecidual característica, apresentavam infiltrado inflamatório entremeado ao tecido conjuntivo fibroso.

Nas oito amostras que não se isolou $C$. pseudotuberculosis, 4 (7,8\% do total de amostras) apresentaram crescimento de Staphylococcus spp., em 1 (1,96\%) amostra isolou-se Escherichia coli e em 3 (5,88\%) não houve crescimento bacteriano.

As lesões histológicas dos linfonodos nos quais se isolou Staphylococcus spp., foram muito semelhantes às encontradas naqueles em que houve crescimento de $C$. pseudotuberculosis, sendo que três apresentaram organização lamelar na área de necrose, em três foram observadas células gigantes, e em duas havia presença de grandes colônias e organização tecidual em camadas (área necrótica rodeada de células epitelióides, linfócitos e plasmócitos e tecido fibroso). Todos os casos nos que não houve isolamento de $C$. pseudotuberculosis foram negativos para tuberculose na coloração de Ziehl-Neelsen.

\section{DISCUSSÃO E CONCLUSÕES}

A prevalência de linfadenite caseosa encontrada no exame ante mortem, portanto considerada clínica, foi de $4,7 \%$, enquanto que a prevalência no exame post mortem foi de $15,9 \%$ o que evidencia uma alta frequência de doença subclínica, que em condições de campo é uma das principais dificuldades para o controle da enfermidade. No Rio de Janeiro foram estudados 13 rebanhos de caprinos, 10 dos quais estavam infectados, com uma prevalência média de $12,2 \%$ de animais com sinais clínicos e $22,5 \%$ de animais infectados (Langenegger et al. 1991). No entanto, nesse levantamento os animais com lesões subclínicas foram detectados mediante exame sorológico e mediante o teste alérgico (Langenegger et al. 1991), enquanto que neste trabalho foram consideradas como lesões subclínicas as que não foram observadas durante o exame ante mortem, incluindo as lesões de órgãos internos que representaram 14,55\% (39/268) das lesões, e as de linfonodos periféricos que não foram detectadas no exame ante mortem. Considerando que, provavelmente, animais com lesões clínicas evidentes não sejam, na sua maioria, enviados para abate, é provável que as prevalências nas fazendas de origem dos animais sejam maiores que as detectadas neste trabalho, o que evidencia a importância econômica da linfadenite caseosa para a ovinocultura da região nordeste. Além disso, a difusão da doença é comprovada pelo fato de que em todos os lotes foram encontrados animais com linfadenite caseosa (Quadro 3) o que demonstra a ampla distribuição da doença na região Nordeste. Em rebanhos comerciais do nordeste a prevalência de caprinos o ovinos com lesões clínicas de linfadenite varia de $5 \%$ a $50 \%$ (Silva \& Silva 1982, Riet-Correa et al. 2003, Alves et al. 2007, Andrade 2007). A alta prevalência de lesões de linfadenite encontrada no frigorífico no qual foi realizado este estudo sugere que, além dos prejuízos causados pela doença por perdas na produção, morte de animais e custos de tratamento devem ser consideradas as perdas por condenação de vísceras e carcaças.

Uma das causas da alta prevalência da enfermidade na região Nordeste seria a presença de numerosas plantas cactáceas, que causam ferimentos na pele de caprinos e ovinos, favorecendo a infecção por Corynebacterium pseudotuberculosis (Unanian et al. 1985, Langenegger et al. 1991). Constata-se uma prevalência maior em caprinos em pastagens nativas sem desmatar do que em caprinos em pastagem nativa desmatada (Silva \& Silva 1982). Outro fator determinante da alta prevalência é o confinamento e à falta de planos de controle sistemático nas fazendas, assim como a falta de controle no transporte e comercialização de animais, o que permite que animais afetados sejam introduzidos nos rebanhos. Um fato importante, que certamente favorece a transmissão é que na região nordeste, ovinos e caprinos, mesmo os criados em condições extensivas, geralmente são encerrados à noite (Riet-Correa 2007). Para Silva (1972), a prevalência da linafadenite caseosa varia muito, parecendo ser maior em criações confinadas ou quando os 
animais são mantidos em pastagens, mas durante a noite recolhidos em abrigos do que em rebanhos mantidos somente em pastagens.

A maior prevalência observada em fêmeas (17,9\%) do que em machos $(13,8 \%)$ é devida, provavelmente, a maior idade de abate das fêmeas, que permanecem por mais tempo nas fazendas do que os machos.

No exame post mortem o linfonodo que apresentou o maior número de lesões foi o pré-escapular com 97 (36,3\%) do total de 268 lesões encontradas, seguido do linfonodo parotídeo com $60(22,4 \%)$ e o linfonodo pré-crural com 56 $(20,9 \%)$ (Quadro 1). Esses resultados são semelhantes aos descritos por Smith \& Sherman (1994), Silva \& Silva (1982) e Unanian et al. (1985). Em caprinos a distribuição das lesões deve-se, provavelmente, a que esses linfonodos drenam áreas de pele que são mais frequentemente lesionadas por escoriações ou traumatismos durante 0 pastoreio ou durante o consumo de folhas de árvores e arbustos (ramoneio), o que facilita a penetração do agente causal (Smith \& Sherman 1994). Por outro lado as lesões dos linfonodos da cabeça (parotídeos, submandibulares e retrofaríngeos) podem ser devidas a infecção pela via oral durante o pastoreio (Fontaine \& Baird 2008). Em ovinos a distribuição das lesões é variável: enquanto na Inglaterra a maioria das lesões é encontrada na cabeça e pescoço, em outros países as lesões são encontradas em outras regiões do corpo (Fontaine \& Baird 2008), o que provavelmente representa infecções em consequência de tosquia e outros traumatismos de pele. Neste trabalho a distribuição das lesões, semelhante à observada em caprinos, é, aparentemente, conseqüência de infecção através da pele da região anterior do animal e pela via oral. Em ovinos, no semiárido, como acontece em caprinos, a infecção parece ocorrer, principalmente, durante o pastejo normal ou comendo arbustos de folhas largas (ramoneio) podem se infectar pela via oral ou por pequenos traumatismos sofridos na região anterior do corpo. O ramoneio em árvores e arbustos da caatinga, apesar de ser um hábito preferencial de caprinos, que utilizam a posição bipedal para se alimentar, também é observado em ovinos deslanados.

Quanto às lesões de órgãos e linfonodos internos, os linfonodos mediastínicos e brônquicos foram os mais afetados, com $30(11,2 \%)$ de um total de 268 lesões encontradas. Também foram encontradas lesões no pulmão, fígado e linfonodos ilíacos (Quadro 1). Apesar de que para alguns autores as lesões dos linfonodos da cavidade torácica e pulmão ocorrem pela via aerógena, o mais provável e que sejam disseminadas provenientes de lesões em outras regiões (Fontaine \& Baird 2008). A importância das lesões pulmonares é dada pela possibilidade de disseminação do agente no meio ambiente após a ruptura desses abscessos (Fontaine \& Baird 2008).

Nesta pesquisa os estudos bacteriológico e histopatológico comprovaram que na grande maioria das lesões diagnosticadas como linfadenite caseosa durante a inspeção post mortem é confirmado o diagnóstico no exame laboratorial. Histologicamente, as estruturas lamelares, características das lesões da linfadenite caseosa (Fontaine \& Baird 2008), foram observadas em 25 de 39 cortes histológicos nos que foi possível visualizar a área de necrose, demonstrando que essa lesão pode estar ausente em abscessos causados por $C$. pseudotuberculosis. Por outro lado a presença de grandes colônias descrita como característica das infecções por $C$. paratuberculosis, mas que ocorre também em lesões causadas por Yersinia spp., Actinomyces spp., Actinobacillus spp., Corynebacterium spp., Staphylococcus spp. e Streptococcus spp. (Brown 2006), foram encontradas na área de necrose em 23 dos 39 linfonodos, o que sugere que esta lesão também não deve ser considerada como a única característica a ser analisada para o diagnóstico da doença. Além disso, pode se concluir que a mineralização, observada em 38 de 39 linfonodos nos que foi observada a área de necrose, é muito freqüente na linfadenite caseosa. Outra lesão frequente é a presença de células gigantes que foi encontrada em 21 linfonodos. Essas duas alterações são encontradas, também, na tuberculose, uma doença, provavelmente, de importância crescente nos rebanhos nacionais de caprinos (Pignata et al. 2009), mas que aparentemente não tem sido diagnosticada em ovinos.

As lesões nas que foi isolado Staphylococcus spp. foram muito semelhantes às causadas por $C$. pseudotuberculosis o que demonstra que o diagnóstico histológico não pode ser utilizado como único critério de diagnóstico da linfadenite caseosa. No entanto, existe a possibilidade de que em lesões causadas por $C$. pseudotuberculosis, contaminadas por Staphylococcus spp., seja isolado unicamente este último, que cresce mais rapidamente e pode inibir o crescimento de $C$. pseudotuberculosis. Isso demonstra, também, a importância de se utilizar técnicas corretas de coleta, transporte e processamento das amostras para o isolamento do microrganismo. Em trabalhos anteriores o isolamento de C. pseudotuberculosis de lesões semelhantes não é constante, observando-se crescimento de outras bactérias (Unanian et al 1985, Andrade 2007, Al-Gaabary et al. 2009). Em geral é mais frequente o isolamento de lesões agudas do que nas crônicas e nestas últimas pode haver lesões estéreis (Baird \& Fontaine 2007, Al-Gaabary et al. 2009).

As lesões histológicas características de linfadenite caseosa não são patognomônicas, mas permitem o diagnóstico presuntivo da doença; no entanto, estas lesões podem ser confundidas com lesões causadas por outros organismos piógenos e com tuberculose, portanto métodos bacteriológicos e histológicos são imprescindíveis para o diagnóstico definitivo da linfadenite caseosa.

Agradecimentos.- Aos Inspetores e Auxiliares do Serviço de Inspeção Federal do MAPA/PB, bem como ao proprietário do Frigorífico, pelo auxilio e apoio na realização desta pesquisa.

\section{REFERÊNCIAS}

Al-Gaabary M.H., Osman S.A. \& Oreiby A.F. 2009. Caseous lymphadenitis in sheep and goats: Clinical, epidemiological and preventive studies. Small Rumin. Res. 87(1):116-121. 
Alves F.S.F., Santiago L.B \& Pinheiro R.R. 2007. Linfadenite caseosa: o estado da arte. Documentos, Embrapa Caprinos, Sobral. 60p.

Andrade J.S.L. 2007. Linfadenite caseosa em ovinos e caprinos criados nas micro-regiões de Piancó e Itaporanga-PB: inquérito e fatores de risco associados à doença. Dissertação de Mestrado em Medicina Veterinária, Centro de Saúde e Tecnologia Rural, Universidade Federal de Campina Grande, PB. 71p.

Brown C. 2006. The Armed Forces Institute of Pathology, Department of Veterinary Pathology, Conference 2, Case I, 8688 (AFIP 2985463).

Fontaine M.C. \& Baird G.J. 2008. Caseous lymphadenitis. Small Rum. Res. 76:42-48.

Langenegger J., Langenegger C.H. \& Scherer P.O. 1991. Prevalência e diagnóstico comparativo da linfadenite caseosa em caprinos do Estado do Rio de Janeiro. Pesq. Vet. Bras. 11:31-34.

Murray P.R., Baron E.J., Pfaller M.A., Tenover F.C. \& Yolken R.H. 1999. Manual of Clinical Microbiology. $7^{\text {th }}$ ed. American Society for Microbiology, Washington, DC. 846p.

Pignata W.A., Alves C.J., Azevedo S.S., Dantas A.F.M., Gomes A.A.B., Remígio F.R. \& Lima F.S. 2009. Prevalência para tuberculose caprina no semi-árido paraibano. Pesq. Vet. Bras. 29(7):526-532.

Radostits O.M., Gay C.C., Hinchcliff K.W. \& Constable P.D. 2007. Veterinary Medicine. $10^{\text {th }}$ ed. W.B. Saunders, Edinburgh, p.795-798.
Riet-Correa F. 2007. Linfadenite caseosa, p.347-352. In: Riet-Correa F., Schild A.L., Lemos R.A.A. \& Borges J.R. (Eds), Doenças de Ruminantes e Eqüídeos. $3^{\text {a }}$ ed. Pallotti, Santa Maria.

Riet-Correa F., Tabosa I.M., Azevedo E.O., Medeiros R.M., Simões S.V.D., Dantas A.F., Alves C.J., Nobre V.M.T., Athayde A.C., Gomes A.A. \& Lima E.F. 2003. Doenças dos ruminantes e eqüinos no semi-árido da Paraíba. Semi-Árido em Foco, Patos, 1:2-86.

Silva F.M. 1972. Caroço dos caprinos (linfadenite caseosa) no estado de Pernambuco. Monografia, UFRPE, Recife. (Apud Langenegger et al. 1991)

Silva M.U.D. \& Silva A.E.D.F. 1982. Linfadenite caseosa em caprinos: observações clínicas de dois anos. Anais $18^{\circ}$ Congresso Brasileiro de Medicina Veterinária, Santa Catarina, p.49.

Smith M.C. \& Sherman D.M. 1994. Goat Medicine. Lippincott Williams and Wilkins, Baltimore, p.46-49.

Unanian M.M., Silva F.A.E.D. \& Pant K.P. 1985. Abscesses and caseous lymphadenitis in goats in tropical semi-arid North-East Brazil. Trop. Anim. Health Prod. 17(1):57-62.

Veschi J.L. 2005. Linfadenite caseosa. Anais VII Encontro de Caprinocultores do Sul de Minas Gerais e Média Mogiana. Espírito Santo do Pinhal. Disponível em <http:/www.capritec.com.br-anais> Acesso em 26 de junho de 2006. 